\title{
Primary oral health care and smiles for life curriculum adaptation for nurses training in low income countries: A case of Tanzanian context
}

\author{
Masunga K. Iseselo *1, Irene Kida Minja ${ }^{2}$, Robin Toft Klar ${ }^{3}$, Katherine Gallant ${ }^{3}$, Serena Kassam ${ }^{4}$, Marion J. \\ Bergman $^{3,5}$ \\ ${ }^{1}$ Department of Clinical Nursing, Muhimbili University of Health and Allied Sciences, Tanzania \\ ${ }^{2}$ Department of Restorative Dentistry, Muhimbili University of Health and Allied Sciences, Tanzania \\ ${ }^{3}$ Rory Meyers College of Nursing, New York University, United States \\ ${ }^{4}$ College of Dentistry, New York University, United States \\ ${ }^{5}$ Miracle Corner of the World, United States
}

Received: August 19, 2016

DOI: $10.5430 /$ jnep.v $7 \mathrm{n} 4 \mathrm{p} 43$
Accepted: November 11, $2016 \quad$ Online Published: November 22, 2016

URL: http://dx.doi.org/10.5430/jnep.v7n4p43

\begin{abstract}
Primary oral health care is essential for the overall wellness of all client populations, especially those living in rural communities. Nurses make up the majority of primary care providers in Tanzania. An opportunity for the lead author to participate as an Oral Health Global Scholar allowed for the exchange of interprofessional oral health knowledge and practice competencies and for the adaptation of a U.S. based oral health curriculum to meet the context of care in Tanzania. This paper identifies the gap in oral health care in Tanzania, describes the knowledge and practice exchanges, and next steps with the adaptation of the Smiles for Life curriculum in Tanzania. The aims is to share interprofessional experience designed to develop a user-friendly curriculum and train primary health care nurses in Tanzania, on applying modern concepts such as a collaborative approach in management of the oral health needs of the patient. Nursing is a profession that has multiple roles and functions which can be utilized according to the situation and need of the community served. Therefore, interprofessional collaborations among health care providers are important to the improvement of quality oral health services.
\end{abstract}

Key Words: Oral health, Curriculum, Nurses, Interprofessional practice

\section{INTRODUCTION}

\subsection{Global burden of oral disease/oral health in Tanza- nia}

The burden of oral disease is a global public health issue. According to the FDI World Dental Federation in 2015, untreated tooth decay is the leading health condition of all 291 conditions contributing to overall global health burden. We know that tooth decay leads to both local and systemic health conditions (FDI World Health Federation) and that the resulting pain from tooth decay is experienced by 25 percent of children between the ages of 2-6 in the United States and beyond, causing absence from school and poor classroom performance. ${ }^{[1,2]}$

In Tanzania, like most developing countries, an increase in

\footnotetext{
*Correspondence: Masunga K. Iseselo; Email: masungaiseselo@yahoo.com; Address: Department of Clinical Nursing, Muhimbili University of Health and Allied Sciences, Tanzania.
} 
oral disease is expected due to changes in lifestyle such as the popularity and availability of sugary diet that is growing faster than access to preventive services. A study conducted to determine the cause of tooth loss among adults in Tanzania in the last decade revealed that caries was the principle cause of tooth loss and molar teeth were the teeth most commonly lost. $^{[3]}$ It is also known that the loss of permanent teeth can result from various events, either the teeth are extracted by dental care providers or they can be lost spontaneously due to progression of oral disease or other events such as dental trauma. ${ }^{[4]}$ Most of the people in Tanzania have little knowledge and skills on healthy lifestyle and behavior that promotes good oral health. ${ }^{[5,6]}$ Dental and oral health problems affect almost all age groups of population in Tanzania. Children are most affected with dental caries and trauma. A survey involving three districts was conducted in 2001 to determine the prevalence of teeth with untreated dental trauma among pre-and primary school in Dar es Salaam reported higher percentage of untreated dental traumas among children. ${ }^{[7]}$ Dental caries, supragingival plaque and calculus are also reported as common problems among secondary students. ${ }^{[8]}$ There is lack of necessary information to the community about the importance of early management of dental trauma, methods of prevention and appropriate handling of injured teeth and if adequately addressed to the community, it will help to minimize the rate of dental injuries and the related complications.

Early childhood caries (ECC) in Tanzania and other East African countries is common with prevalence ranging from $3.7 \%$ to $30.1 \%$ in different regions. ${ }^{[9-11]}$ Prevalence of caries is higher in children under the care of the guardians, children who sleep with breast in the mouth and those with higher sugar moments as the result of snacking. ${ }^{[10]}$ Oral health education aimed at caretakers of children, including health care workers' information related to adverse consequences for oral health of frequent sugar consumption and poor oral hygiene is important for prevention of ECC. ${ }^{[11]}$

Fluorosis is endemic throughout the East African Rift valley, including parts of Tanzania. A study conducted in Hai District to determine the prevalence and associated factors reported more than $75 \%$ of individual with juvenile skeletal fluorosis had dental fluorosis. ${ }^{[12]}$ Although the reason for dental fluorosis is not well clearly documented, location, fluoride in trona, commonly known as magadi, other elements found in magadi, and malnutrition are the factors which are considered to be contributing to the severity of dental fluorosis. ${ }^{[13]}$

Oral health care services in most of low resource setting are not adequately provided. In Tanzania, oral health screening services in primary health settings, particularly in reproductive and child health is inadequately addressed partly because the health care providers in these settings have little knowledge ${ }^{[14,15]}$ and is partly due to the shortage of the oral health workforce. ${ }^{[16-18]}$ In South Africa, like in Tanzania, there is minimal integration of oral health education at reproductive and child health sites. ${ }^{[19]}$ According to this finding in South Africa; reproductive and child health sites remain important sites for integration of dental and oral health care with general health services. This helps in complementing efforts for prevention of early childhood caries. In Nigeria, primary health care workers reported to have deficiency of knowledge on the cause of common oral diseases and recommended oral health education to be included in future curriculum of these personnel. ${ }^{[20]}$ All these findings substantiate the need of oral health education in low resource countries

\subsection{Dental care in Tanzania}

It is known that oral pain is the major cause of attendance at all public dental clinics in Tanzania. ${ }^{[21]}$ However, only a quarter of those who experience oral pain or discomfort sought emergency oral care from oral health care facilities. This indicates that most of them use self-medication as an alternative to using oral care facilities especially in the rural community. All age groups experience dental problems and would need to seek treatment. However, health facilities that provide oral health are very few especially in the rural communities. A study conducted in coast region in Tanzania revealed that about half of the elderly had a problem oriented care. ${ }^{[22]}$ The most common oral care carried out in public dental clinics is tooth extractions. ${ }^{[23-25]}$ Additionally, the limited number of dental clinics that offer restorative care in Tanzania has been as an obstacle towards accessing restorative services when needed. ${ }^{[24,25]}$ There are other barriers to restorative services including shortage of equipment, lack of funds to purchase materials and dental materials not being available. ${ }^{[25]}$

Human resource for health in Tanzania is a long standing problem. Although the government is struggling to employ various health care cadres especially in the rural areas, the shortage is still alarming. A study conducted in a recent year revealed that only $14 \%$ of the recommended number of nurses and $20 \%$ of the clinical staff had been employed at the health facilities. ${ }^{[18]}$ Human resources for health constraints are more severe in oral health arenas. According to the ministry of health, community development, gender, elderly and children (MoHCDGEC) report of 2012/2013, Tanzania had dentist-to-population ratio of 1:120,000 which is very low compared to that recommended by the World Health Organization of 1:7,500. Although the number of dentists will 
have increased by now, the shortage of dentists is astonishing. The oral health workforce plus economic limitations on the delivery services require innovation - new ways that this scarce resource, could be utilized to maximum benefit for the population.

Most dental services in Tanzania are rendered in hospitals. Despite the initiative of the MoHCDGEC to provide hospitals and health centres with dental equipment, a severe shortage of dental materials for restorative and prosthodontic therapy persists. According to Loomer et al, Oral health services in Tanzania is provided by different levels of care providers including dental therapists (DTs) who have 3 years of postsecondary school training, assistant dental officers (ADOs), who have at least 5 years of professional experience and who then complete 2 years of training. ${ }^{[26]}$ DTs mainly practice in district hospitals where they also participate in oral health education. ADOs usually perform administrative roles, such as training and supervision of other health personnel, as well as patient care responsibilities. However, these dental care providers are unevenly distributed throughout the country. Dentists and other dental specialists are very few and most concentrated in referral hospitals leaving most of the primary health facilities without dental professionals.

\subsection{Nursing training and oral health care in Tanzania}

Nurses and midwives make the largest health workforce in Tanzania. It is the largest group of health care providers distributed throughout the country. All nurses working in Tanzania have to be licensed as either registered or enrolled nurses by Tanzania nurses and midwives council (TNMC). Currently, the training of nurses occurs at different levels. These are at the certificate, diploma, bachelors and masters levels.

From 2008 to 2011, all curricula at the Muhimbili University of Health and Allied Sciences (MUHAS) in Tanzania were transformed from knowledge-based to competency-based. ${ }^{[27]}$ The competencies includes: professional knowledge and practical/clinical skills with emphasis on relationship with patients, clients and communities at large. Relationship with colleagues and teaching skills, maintaining good practice, working within the health care system and maintaining professionalism are other prerequisite areas. In the nursing curriculum for a Bachelor of Science in Nursing $(\mathrm{BScN})$, nursing assessment is taught in the Principles of Nursing course, which provides the basic knowledge and skills for the nursing profession. In this course, however, there is inadequate content in the oral aspects of the nursing assessment and intervention to support the competency of providing a thorough oral examination. This has resulted in cadres of nurses lacking the complete set of comprehensive assessment

Published by Sciedu Press skills including oral cavity examination.

The diploma level nursing institutions, where the training is mostly under the Ministry of Health, community development, gender, elderly and children, are required to ensure that training programs are supported by curricula pegged to National Technical Award (NTA) levels that indicate the recommended competencies to be possessed by students. Curricula are developed by following National Accreditation Council for Technical Education (NACTE) requirements on the needed competencies. The curricula used in these institutions from which most nurses graduate address very little of the oral health components. This underscores the importance of using the type of the curriculum and model of learning that is relevant to the population served. It should not only equip the graduates with the knowledge, skills, attitudes and behaviour but also should accommodate the culture and social principles acceptable to the community they serve for achieving the best outcome. ${ }^{[28]}$

Nurses and midwives provide health services in all levels of health facilities. Nurses can play a pivotal role in expanding access to overall health care for the population. Evidence has shown that primary health care nurses can be appropriately trained on oral health matters by increasing their knowledge and skills to reach the underserved population. ${ }^{[29-31]}$

Involvement of nurses in provision of oral health care in primary settings has been tested and demonstrated to be effective in some countries. ${ }^{[32,33]}$ However, knowledge and skills is required in this health worker population in order to render their services effectively in this area where there is inadequate human oral health workforce. ${ }^{[34,35]}$

It is known that nurses can play a greater role in expanding the access of oral health care service especially in low income countries like Tanzania. ${ }^{[32]}$ Nurses in Tanzania need to be trained so that they are able to provide adequate and quality oral nursing care to patients especially in the rural areas. This requires dedicated knowledge and skills on assessing and planning interventions for patients with oral health problems. A recent study conducted among nursing students in Tanzania reported poor oral health knowledge among nursing students and recommended that curriculum for nursing education be reviewed in order to encompass comprehensive oral health components. ${ }^{[36]}$

The inadequate provision of oral health services in Tanzania compounded by the shortage of clinicians who can conduct and disseminate evidence-based practice is one of the compelling factors for establishing oral health training course for the nursing sector. According to Judith Haber et al, health care providers have performed the HEENT physical assess- 
ment in the same fashion for centuries. ${ }^{[37]}$ In addition, a majority of primary health care providers, using the traditional HEENT examination, exclude the examination of the oral cavity, and in doing so, omit oral health and its linkage to overall systemic health. Bringing the oral cavity into the HEE'O'NT (HEENOT) exam is one of the way to close the gap between the traditional exams and the new approach ensuring that the oral cavity is not omitted during assessment of patients. ${ }^{[37]}$

This program aims at designing and developing a userfriendly curriculum for training primary health care nurses in Tanzania, applying modern concepts such as a collaborative approach in management of the oral health needs of the patient

\section{INTERPROFESSIONAL EXCHANGE}

\subsection{Background on NYU global scholars program}

As a Global Health Scholar in Oral Health, the first author received intensive training at New York University Colleges of Nursing and Dentistry in developing the oral health curriculum for training nurses working in rural areas. During the process of developing the curriculum, the scholar was guided by faculty mentors from the NYU Colleges of Nursing and Dentistry. He developed the curriculum by adapting the web-based Smiles for Life curriculum, which has interprofessional oral health training content, was developed and designed for a US population, and can be used by all health professionals who come in contact with patients, i.e. dentists, medical doctors, nurses, dental therapists, hygienists and even pharmacists.

Acquisitions of dental and oral health care experience at NYU.

The dental experience gained encompassed all three areas of experience:

(1) Paediatric Dental Clinics

(2) Community dental outreach and

(3) Paediatric oral health interprofessional clerkship

\subsubsection{Dental clinic experience}

Through mentorships and coaching, the scholar observed various dental procedures at NYU Dental Hospital including tooth extraction, sealants, fluoride treatment, athletic mouth guards, fillings, and space maintainers. The paediatric dental treatment and disease prevention at NYUCD is provided for children up to 14 years of age, with special facilities for newborns and infants. Weekly attendance to this clinic was maintained for the periods of 8 weeks of stay in NYC. This provided enough time for the scholar to learn and acquire experience that can be transferred and practiced by Tanzanian population. The scholar also attended and observed oral medicine clinics. This is an adult dental clinic that deals with adult oral health problems such as oral cancers.

\subsubsection{Community dental outreach program}

There is extensive practice of community dental outreach in NYC which is sponsored by Henry Schein Cares Global Student Outreach Program facilitates travelling throughout the five boroughs of New York City to provide care to underserved populations. The services provided include screenings and education in public schools and childcare centres, exams and fluoride varnish for preschool-aged children in different centres (Head Start), school-based sealant program, participating in numerous health fairs and community events, such as Special Olympics events. The scholar attended these programs and gained experience. This program is far more compreshensive than what occurs in Tanzania, where there is no regular community based dental health program. It was a learning experience for the author to have such observation in all aspects of the community programs.

\subsubsection{Paediatric oral health interprofessional clerkship}

Through the Oral Health Nursing Education Practice (OHNEP) and Teaching Oral-Systemic Health (TOSH) programs, the scholar was able to gain oral health experience by hands-on practice during an oral health interprofessional paediatric clerkship program at Bellevue Hospital that helped in developing the training materials.

In this program, nursing, dental, and medical students were providing dental services to children attending the clinic. Collaborative assessment of dental and oral health of children aimed at gaining specific competencies that could be applied independently in poor resource areas. Competencies for dental students were to take a comprehensive approach to assessing patient general health needs; identify need for referral such as primary care, dietary counselling and social work. For nurses competencies were to recognize normal and pathological variations of oral structures and to demonstrate head and neck and oral examinations. However, the prerequisite competences for both dental and nursing students was to establish the oral-systemic association in the context of diagnosis, treatment and planning in orders to address the patient's oral health needs; assess the role of nursing in dentistry in providing primary care.

During the process of acquiring this knowledge and experience about oral health programs, there were regular skype conferences involved mentors from Ministry of Health and MUHAS in Tanzania and that from NYUCN on the required contents to be incorporated in the curriculum. That means knowledge and experience was shared with experts in nursing and dentistry so that contents in the curriculum would reflect cultural aspects for the Tanzanian population. 
The scholar used Smiles for Life content to develop a userfriendly oral health curriculum.

\subsection{General changes made in Smiles for Life curriculum}

In most teaching content the word "Clinician" was replaced with "Nurse" so that the contents can be interchangeable for nurses in Tanzania. In this context "Education Objectives" were replaced by "Module Learning Outcomes" and "Chapter Objectives" with "Learning Outcomes". Also the word "session" was added in every new idea addressed in the module and numbered numerically. Most modules have 3-5 sessions.

The main purpose of doing this was to make the curriculum to be more competence-based rather than knowledge-based. Training institutions in Tanzania have adopted competencebased education which is geared towards increasing productivity, providing a career ladder for higher learning skills opportunities and competencies, and achieving a more responsive education and training system, aligned with health sector employment needs. ${ }^{[38]}$

Some words in the Learning Outcomes were replaced by "appropriate words" according to Bloom's Taxonomy to en- compass the three domains of learning. ${ }^{[39]}$

The consent to modify the contents to fit the context of Tanzania was sought from relevant authority. The editorial team of the Smiles for Life curriculum was consulted. Specific direction was given to follow during the process. Feedback was sent to the editorial team and all changes made were scrutinized to ensure that the quality of the content was not compromised.

The modules consist of didactic components which prepare the nurse to acquire knowledge related to various aspects of oral health problems. The knowledge piece is complimented by hands-on activities as well as test questions, resources for further learning, oral health web links, an implementation guide, and detailed module outlines. Video clips and illustrations enrich most areas of this course

\subsection{Interprofessional core competencies in oral health}

The interprofessional core competencies as described in some documents ${ }^{[40,41]}$ have been valuable resources for teaching nursing in primary health care. With material from Smiles for Life, authors identified core competences that are relevant to the Tanzania contexts as in Table 1 below.

Table 1. Interprofessional core competences for oral health training

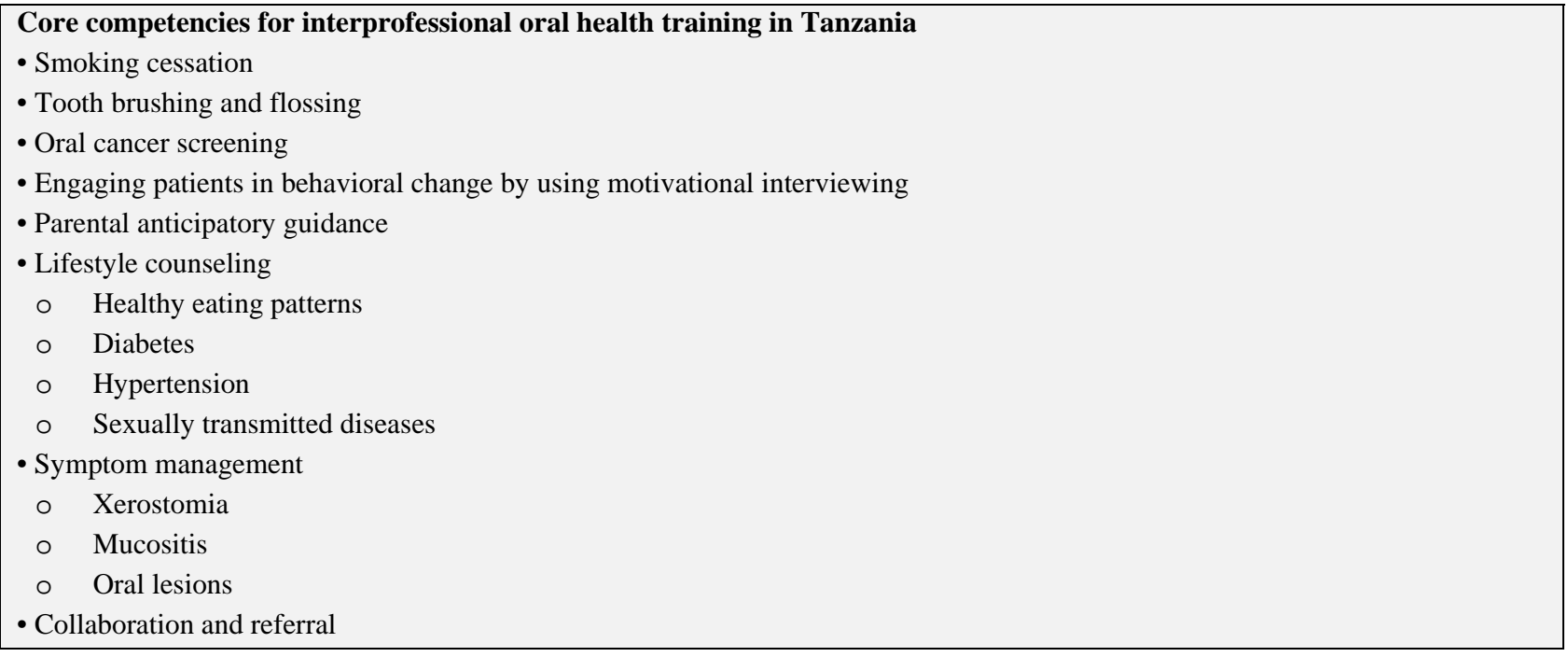

Note. Source: Smiles for Life; A National Oral Health Curriculum

\section{IMPLICATIONS FOR FUTURE PRACTICE}

\subsection{Pilot project}

The focus of this course is to improve primary oral health care through oral health promotion, education, prevention and emergency care. ${ }^{[42]}$ It also promotes the integration of oral health into general health promotion and chronic disease prevention as the risks to oral diseases are closely linked to systemic health. However, at present, some major challenges need to be overcome such as the translation of knowledge and experience in oral health practice including prevention and health promotion programmes. The specific areas that have gained support from the WHO include effective use of fluoride varnish, healthy diet and nutrition pattern, tobacco control, oral health of children and youth through promotion at schools, and oral health improvement for the general population and the elderly. ${ }^{[43]}$ These priorities, as well as 
the strategic areas for improving oral health in the general population will be addressed in this course. Introduction of this course in Tanzania provides a comprehensive approach in assessing the health problems of the patient using an interprofessional approach to tackle the oral and systemic connections of oral diseases. The course also focuses on current practice especially on teaching evidence-based principles and systems to ensure an optimal outcome for patient care. Oral health in pregnancy, infants and children as well as in adults with more emphasis on preventive strategies of all group populations is also adequately addressed in the curriculum. This course will improve the theoretical background and practical skills on oral health care for nurses with the expected outcome of increasing oral health workforce and thereby expanding access to oral health for the population of Tanzania.

The training using this curriculum prepares nurses with competencies to recognize the risk for oral disease through competent oral examinations, and to provide oral health promotion and intervention in the health facilities and in the communities. It also prepares nurses to assess and accurately define the oral health problems and make appropriate clinical decision and referrals.

Nurses are well positioned to play a pivotal role in expanding access to overall health care for the population. Supporting nurses with knowledge and skills to implement evidencebased oral health services can improve access to needed care and reduce health disparities in Tanzania

\subsection{Projections on how the pilot will improve oral health in Tanzania}

Promoting oral health is the foremost population health goal worldwide; however, curricula preparing health professionals have inadequate oral health contents and clinical experiences. The national public health challenge to improve access to oral health, leading to decreased health disparities and improving both oral health and overall health outcomes requires building an interprofessional workforce capacity among nondental providers. ${ }^{[37]}$

This is an important course for nurses working in primary health care in low income countries such Tanzania. In poor communities, nurses who are involved with primary patient care are usually the first health care professionals to come into contact with the general public. An example of areas which need more focus and where nurses come into contact with the general public is in reproductive and child health clinics. Primary health care nurses can do multiple screenings in these health care services. The nurse can assess the child for any oral health problems and counsel the mother accordingly for oral disease prevention. Pregnant mothers attending an antenatal clinic should be counseled on proper oral health care to minimize risk of complications to the newborn. These practices have been effective in other countries where the oral and dental care is part of the package for reproductive and child health services. ${ }^{[45]}$

This course is also equally important to nurses who are working in intensive care units (ICU). The need for implementation of advanced oral health training for ICU nurses has been reported in Sudan. ${ }^{[46]}$ In general, knowledge, skills and attitude of nurses to use HEEN'O'T as a prototype for nursing assessment is a prerequisite for provision of quality care in all settings. In hospital settings nurses are providers of various nursing care. However, mouth and oral care is often forgotten. In primary health care, nurses are the care providers that make up the major health work force especially in low income countries. Training nurses working in primary health care will provide an innovative solution to addressing both the shortage of oral health care providers and the knowledge deficit for those already working in such environments.

This course supports the importance of the life-long learning needs of nurses because no one can learn all the necessary clinical information for practice during a short training period. ${ }^{[47]}$ Clinical practice is dynamic and ever-changing as more evidence is accumulated and disseminated. For example, as new diseases continue to emerge, the development of new technology, treatment equipment requires continuing education and professional development. ${ }^{[28]}$ While we are implementing this curriculum for training nursing in Tanzania, there is a great step made towards bridging the oral health disparities in low income countries by infusing this oral curriculum into existing curricula of the training institution. ${ }^{[29]}$ Similarly, oral health training for nurses in Tanzania will be strategically implemented and infused into the existing curricula in order to promote effectiveness and sustainability.

\section{Conclusion}

Training of primary health care nurses on the aspects of oral health using a culturally adapted, user-friendly curriculum is an important and innovative method in strengthening oral health care services in the community. It also provides clinical guidance and the means to increase the knowledge base of healthcare professionals regarding oral health problems and diseases. Increasing awareness of oral health specifically for nurses and community populations in resource-poor areas will allow for healthcare professionals to assist patients with oral diseases in optimizing health and decrease morbidity and mortality in the Tanzanian community. 


\section{LESSONS LEARNED}

Nursing is a profession that has multiple roles and functions that can be adopted according to the situation and need of the community served. Oral health nursing is an area which is not effectively practiced in most countries especially in low resource settings. The experience gained by the author in U.S is an important indicator to plan and implement oral health nursing practice in Tanzania. Interproffesional collaborations among health care providers is the key to the access of quality oral health services

\section{THE WAY FORWARD}

In collaboration with other stakeholders from the MoHCDGEC there will be a demonstration program of training nurses in a selected region of Tanzania that will involve government, academic and private sector partners. This pilot study will be preceded by training of trainers (TOT). Evaluations of the pilot study will be done to ascertain its effectiveness and will be disseminated accordingly. Following the evaluation, the demonstration program will be scaled up for roll out to other areas of Tanzania. The work will be refined and finalized making adjustments as needed based on external review by experts and national stakeholders. To ensure sustainability, the program will integrate oral health modules to all level of nursing training curricula e.g. certificate to masters level.

\section{ACKNOWLEDGements}

Special thanks go to Dean Eileen Sullivan-Marx and to NYU Rory Meyers College of Nursing Global Initiatives for hosting the program and providing support. Special thanks go to Kerry Stalonas, Assistant Director of Global Operations. Also many thanks to be channeled to Miracle Corners of the World Director of Healthcare Projects for the commitment and support. I would also like to acknowledge the Tanzanian Ministry of Health, Community Development, Gender, Elderly and Children through the Permanent Secretary for making this program part of the government's strategy to increase the oral health workforce. I would like to extend my thanks to the OHNEP and TOSH programs team at NYU Rory Meyers College of Nursing and residents from NYU College of Dentistry through its Pediatric Interprofessional Clerkship and Pediatric Dental outreach program and MUHAS Department of Community Nursing.

\section{CONFLICTS OF INTEREST Disclosure}

The authors declare that there is no conflict of interest.

\section{REFERENCES}

[1] Krisdapong S, Somkotra T, Keakulpipat W. Disparity in early childhood and its impact on oral health-related quality of life of preschool children. Asia-Pacific J Public Heal. 2014; 26(3): 2014.

[2] Jackson SL, Vann WF, Kotch JB, et al. Impact of poor oral health on children's school attendance and performance. Am J Public Health. 2011; 101(10): 1900-6. PMid:21330579 https://doi.org/10.2 105/AJPH. 2010. 200915

[3] Kida I, Astrøm AN, Strand GV, et al. Clinical and socio-behavioral correlates of tooth loss: a study of older adults in Tanzania. BMC Oral Health. 2006; 6: 5. PMid:16536880 https://doi.org/10.1 186/1472-6831-6-5

[4] Petersen PE, Yamamoto T. Improving the oral health of older people: The approach of the WHO Global Oral Health Programme. Community Dent Oral Epidemiol. 2005; 33(2): 81-92. PMid:15725170 https://doi.org/10.1111/j.1600-0528.2004.00219.x

[5] Åstrøm AN, Masalu JR. Oral health behavior patterns among Tanzanian university students: A repeat cross-sectional survey. BMC Oral Health [Internet]. 2001; 1: 1-7. PMid:11801201

[6] Masalu JR, Kikwilu EN, Kahabuka FK, et al. Oral health related behaviors among adult Tanzanians: a national pathfinder survey. BMC Oral Health [Internet]. 2009; 9(1): 22. PMid:19751519 https://doi.org/10.1186/1472-6831-9-22

[7] Kahabuka Fk, Plasschaert A, Hof V, et al. Prevalence of teeth with untreated dental trauma among nursery and primary school pupils in Dar es Salaam, Tanzania. Dantal Traumatol. 2001; 17: 109-13. https : //doi.org/10.1034/j.1600-9657.2001.017003109.x

[8] Carneiro LC, Kabulwa MN. Dental Caries , and Supragingival Plaque and Calculus among Students, Tanga, Tanzania. ISRN Dent. 2012; 2012.

[9] Maro D kahabuka F. Prevalence of early childhood caries among 2-6 years old underprivileged children in Dar es Salaam. Tanzania Dent J. 2008; 14(2): 53-8.

[10] Rwakatema DS, Ng'ang'a PM. Early childhood caries in Moshi, Tanzania. East Afr Med J. 2010; 87(7): 304-10. PMid:23451550

[11] Masumo R, Bardsen A, Mashoto K, et al. Prevalence and sociobehavioral influence of early childhood caries, ECC, and feeding habits among 6-36 months old children in Uganda and Tanzania. BMC Oral Health. 2012; 12(1): 24. PMid:22834770 https : //doi.org/10.1186/1472-6831-12-24

[12] Jarvis HG, Heslop P, Kisima J, et al. Prevalence and aetiology of juvenile skeletal fluorosis in the south-west of the Hai district, Tanzania - a community-based prevalence and case-control study. Trop Med Int Heal. 2013; 18(2): 222-9. PMid:23198699 https://doi.org/10.1111/tmi.12027

[13] Yoder KM, Mabelya L, Robison VA, et al. Severe dental fluorosis in a Tanzanian population consuming water with negligible fluoride concentration. Community Dent Oral Epidemiol. 1998; 26(6): 382-93. PMid:9870537 https ://doi.org/10.1111/j.1600-0 528.1998.tb01976.x

[14] Mwangosi IEAT, Kiango MM. Oral health experience during pregnancy and dental service utilization in Bariadi District, Tanzania. 2012; 14(2): 1-7.

[15] Mumghamba EGS, Manji KP. Maternal oral health status and preterm low birth weight at Muhimbili National Hospital, Tanzania: a case- 
control study. BMC Oral Health. 2007; 7(8): 1-12. PMid:17222356

[16] Sirili N, Kiwara A, Nyongole O, et al. Addressing the human resource for health crisis in Tanzania: the lost in transition syndrome. Tanzan J Health Res. 2014; 16(2): 1-9.

[17] Shemdoe A, Mbaruku G, Dillip A, et al. Explaining retention of healthcare workers in Tanzania: moving on, coming to "look, see and go", or stay? Hum Resour Health. 2016 Jan; 14: 2.

[18] Manzi F, Schellenberg JA, Hutton G, et al. Human resources for health care delivery in Tanzania: a multifaceted problem. Hum Resour Health. 2012 Jan; 10(1): 3.

[19] Kolisa Y. Assessment of oral health promotion services offered as part of maternal and child health services in the Tshwane Health District, Pretoria, South Africa. African J Prim Heal care Fam Med. 2016; 8(1): e1-8.

[20] Braimoh M, Ogunbodede E, Adeniyi A. Integration of oral health into primary health care system: views of primary health care workers in Lagos State, Nigeria. J Public Health Africa. 2014; 5: 35-9.

[21] Kikwilu EN, Masalu JR, Kahabuka FK, et al. Prevalence of oral pain and barrier to use oral care facilities among adult Tanzanians. BMC Oral Health. 2008; 7(28): 1-7.

[22] Astrøm AN, Kida IA. Perceived dental treatment need among older Tanzanian adults-a cross-sectional study. BMC Oral Health [Internet] 2007; 7(9)

[23] Mosha HJ, Scheutz F. Perceived need and use of oral health services among adolescents and adults in Tanzania. Community Dent Oral Epidemiol [Internet]. 1993; 21(3): 129-132. https://doi.org/ 10.1111/j.1600-0528.1993.tb00736.x

[24] Kikwilu E, Frencken J, Mulder J, et al. Barriers to restorative care as perceived by ental patients attending government hospitals in Tanzania. Community Dent Oral Epidemiol. 2009; 37(1): 35-44 PMid:19191819 https://doi.org/10.1111/j.1600-0528. 20 08.00446. $\mathrm{x}$

[25] Kikwilu EN, Frencken JE, Masalu JR, et al. Barriers to restorative care as perceived by dental practitioners in Tanzania. Community Dent Health. 2010; 27(1): 23-8.

[26] Loomer PM, Masalu JR, Mumghamba E, et al. New curriculum in dentistry for Tanzania: competency-based education for patient and population health (2008-2011). J Public Heal Policy [Internet]. 2012; 33 Suppl 1(S1): S92-109.

[27] Ngassapa OD, Kaaya EE, Fyfe MV, et al. Curricular transformation of health professions education in Tanzania: the process at Muhimbili University of Health and Allied Sciences (2008-2011). J Public Heal Policy. 2012 Jan; 33(Suppl 1): S64-91.

[28] Mumghamba EG. Integrating a primary oral health care approach in the dental curriculum: a Tanzanian experience. Med Princ Pract. 2014 Jan; 23 Suppl 1(suppl 1): 69-77.

[29] Hahn JE, Fitzgerald L, Markham YK, et al. Infusing oral health care into nursing curriculum: addressing preventive health in aging and disability. Nurs Res Pract. 2012 Jan; 2012: 157874.

[30] Rabiei S, Mohebbi SZ, Yazdani R, et al. Primary care nurses' awareness of and willingness to perform children's oral health care. BMC Oral Health. 2014; 14: 26. PMid:24670004 https : //doi .org/10 $.1186 / 1472-6831-14-26$

[31] Sangappa S, Bhojraj N, Godhi B, et al. Oral health care awareness among nursing students in an Indian school: an experimental study. J Contemp Med Educ [Internet]. 2013; 1(4): 1. https : //doi.org/10.5455/jcme.20130502091323
[32] Thema LK, Shenuka S. Integrated primary oral health services in South Africa: the role of the PHC nurse in providing oral health examination and education. African J Prim Heal Care Fam Med [Internet]. 2013; 5: Art. 413.

[33] Wooten KT, Lee J, Jared H, et al. Nurse practitioners and certified nurse midwives' knowledge, opinions and practice behaviors regarding periodontal disease and adverse pregnancy outcomes. J Dent Hyg. 2011; 85(2): 122-31.

[34] Forsell M, Kullberg E, Hoogstraate J, et al. An evidence-based oral hygiene education program for nursing staff. Nurse Educ Pract [Internet]. 2011; 11(4): 256-9. PMid:21185232 https://doi.org/10 $.1016 / j$.nepr.2010.11.017

[35] Hollaar V, Maarel-Wierink C van der. Nursing Staff's Knowledge about and Skills in Providing Oral Hygiene Care for Patients with Neurological Disorders. J Oral Hyg Heal [Internet]. 2015; 3(6).

[36] Rwakatema DS, Ananduni KN, Katiti VW, et al. Oral health in nursing students at Kilimanjaro Christian Medical Centre teaching hospital in Moshi, Tanzania. BMC Oral Health [Internet]. 2015; 15(1): 23. PMid:25881237 https://doi.org/10.1186/s12903-015-000 8-8

[37] Haber J, Hartnett E, Allen K, et al. Putting the mouth back in the head: HEENT to HEENOT. Am J Public Health. 2015; 105(3): 437-41. PMid:25602900 https://doi.org/10.2105/AJPH. 2014. 3024 95

[38] Ngassapa OD, Kaaya EE, Fyfe MV, et al. Curricular transformation of health professions education in Tanzania: the process at Muhimbili University of Health and Allied Sciences (2008-2011). J Public Heal Policy [Internet]. 2012; 33(Suppl 1): S64-91.

[39] Bloom BS, Engelhart MD, Furst EJ, et al. TAXONOMY OF EDUCATIONAL OBJECTIVES: The Classification of Educational Goals. Benjamin BS, editor. New York; 1956.

[40] Dolce MC. Integratiing oral health into professional nursing practice: An interprofessional faculty tool kit. J Prof Nurs. 2014; 30(1): 63-71. PMid:24503317 https://doi.org/10.1016/j.profnurs . 201 3.06 .002

[41] Schmitt M, Blue A, Aschenbrener CA, et al. Core Competencies for Interprofessional Collaborative Practice [Internet]. Vol. 86, Academic Medicine. 2011.

[42] Nash DA, Friedman JW, Kardos TB, et al. Dental therapists: a global perspective. Int Dent J. 2008; 58(2): 61-70. https : //doi .org/10 $.1111 / j .1875-595 X .2008 . t b 00177 . x$

[43] Petersen PE. World Health Organization global policy for improvement of oral health - World Health Assembly 2007. Int Dent J. 2008; 58: 115-21. https://doi.org/10.1111/j.1875-595X.2008.tb00185.x

[44] Nyamuryekung'e KK, Lahti SM, Tuominen RJ. The relative patient costs and availability of dental services, materials and equipment in public oral care facilities in Tanzania. BMC Oral Health. 2015; 15(1): 74. PMid:26126654 https://doi .org/10.1186/s12903 $-015-0061-3$

[45] Department of Health. Practice Guidelines. 2006.

[46] Ibrahim SM, Mudawi AM, Omer O. Nurses' Knowledge, Attitude and Practice of Oral Care for Intensive Care Unit Patients. Open J Staomatology. 2015; 5: 179-86. https://doi.org/10.4236/oj st. 2015.57023

[47] Davis L, Taylor H, Reyes H. Lifelong learning in nursing: A Delphi study. Nurse Educ Today. 2014; 34(3): 441-5. PMid:23664106 https://doi.org/10.1016/j.nedt.2013.04.014 